\title{
Analisis Sistem Informasi CRM Untuk Meningkatkan Pelayanan dengan Pendekatan SDLC (Studi Kasus: UMKM "SAKTI")
}

\author{
Latjuba Sofyana STT ${ }^{1}$, Andi Rahman Putera ${ }^{2}$ \\ ${ }^{1}$ Fakultas Teknik, Universitas PGRI Madiun, Jalan Setia budi 85, Madiun, 63118 \\ E-mail: latjubastt@unipma.ac.id \\ ${ }^{2}$ Fakultas Teknik, Universitas PGRI Madiun, Jalan Setia budi 85, Madiun, 63118 \\ E-mail: andirahmanputera@unipma.ac.id
}

\begin{abstract}
The development of information technology is endless. Every day there is something new that we can find outside. Will affect many sectors. One of the fastest growing is UMKM. Screen printing and convection is one of the UMKM that produces and sells plain shirts and screen printing. To improve its services, screen printing and convection information systems need to be developed so that the service is more optimal, effective and efficient. Customer Relationship Management (CRM) is a core business strategy that can support, obtain and retain customers. Based on the results of the needs analysis and system analysis of the company that can be known about the CRM modules needed for the system are Customer Service and Support (CSS) and Entreprise Marketing Automation (EMA).
\end{abstract}

Keywords—: Information Systems; CRM; SDLC; Screen printing; Convection.

\section{PENDAhuluan}

Perkembangan teknologi informasi serasa tidak ada habisnya. Setiap hari ada saja hal baru yang bisa kita temukan di luar. Sehingga akan berpengaruh terhadap banyak sektor, seperti usaha, pendidikan, kesehatan dan lain-lain. Sektor usaha yang mempunyai perkembangan yang pesat saat ini salah satunya adalah usaha di bidang sablon dan konveksi. Sablon dan konveksi sangatlah dibutuhkan oleh banyak kalangan, dari anak kecil sampai orang dewasa. Karena kaos merupakan kebutuhan primer bagi masyarakat, usaha ini mempunyai pasar yang luas. Selain itu mode saat ini juga sangat dinamis dan mengikuti perkembangan zaman.

Sablon dan konveksi sakti adalah UMKM yang memproduksi dan menjual kaos polos dan sablon. Sablon dan konveksi sakti saat ini menggunakan teknologi sebagai media promosis melalui instagram, facebook dan shopee. Pada media sosial tersebut sakti menampilkan katalog kaos polos dan sablon yang diproduksi. Namun, berdasarkan hasil wawancara dengan pemilik sakti pemilik usaha kesulitan dalam memantau pelanggan yang memiliki potensi besar agar dapat memberikan pelayanan yang berbeda dari pelanggan lainnya, pemilik usaha juga kesulitan memantau kegiatan produksi. Di bagian produksi kesulitan dalam menentukan list yang harus dikerjakan terlebih dahulu karena tidak ada SOP yang jelas, biasanya bagian produksi menerima perintah langsung dari pemilik mana yang harus dikerjakan terlebih dahulu. Selain itu hasil wawancara dengan bagian keuangan bahwa mereka kesulitan membuat laporan keuangan yang harus diketahui pemilik setiap bulannya. Rekap bulanan mereka tidak dilakukan secara rutin dan masih ditulis manual, sehingga mereka kesusahan apabila terjadi salah hitung dsb Kelemahan tersebut disebabkan belum adanya sistem informasi terintegrasi.

Customer Relationship Management (CRM) merupakan strategi bisnis untuk mengidentifikasi, mendapatkan dan mempertahankan pelanggan (Buttle, 2009). Dengan strategi ini dapat menyelesaikan permasalahan yang ada pada sablon dan konveksi sakti yaitu untuk mempertahankan pelanggannya. Strategi ini memiliki beberapa tipe dan tipe yang dapat digunakan dalam penelitian yaitu Operasional CRM yang berfokus pada otomatisasi bagaimana perusahaan berhubungan dengan pelanggannya (Buttle,2009).

Pengembangan sistem CRM menerapkan konsep SDLC. System Development Life Cycle (SDLC) adalah tahapan-tahapan pekerjaan yang dilakukan dalam membangun sistem informasi (Ayu,2018). Dengan adanya implementasi CRM ini diharapkan dapat membawa sablon dan konveksi sakti untuk mempertahankan loyalitas pelanggannya. Sehingga pelayanan pemesanan akan berbasis komputer dan pengolahan data nya akan terintegrasi.

Oleh karena itu, penulis melakukan penelitian "Analisis Sistem Informasi Customer Relationship Management Untuk Meningkatkan Pelayanan Dengan Pendekatan System Development Life Cycle (SDLC) di UMKM SAKTI”.

\section{METODE PENELITIAN}

Pada tahapan ini dijelaskan tahapan proses yang dilakukan dalam penyelesaian dan penyusunan laporan penelitian ini. Penelitian mengenai CRM untuk Meningkatkan Pelayanan di sablon dan konveksi sakti dengan pendekatan SDLC dilakukan dengan tahapan - tahapan dibawah ini: 


\section{A. Studi Pustaka}

Studi pustaka yaitu melihat dan membaca beberapa literatur bacaan yang telah ada sebagai referensi, antara lain :

1. Menggali informasi di internet mengenai Customer Relationship Management

2. Menggali informasi dari berbagai situs internet mengenai System Development Life Cycle

3. Mencari informasi mengenai usaha konveksi dan sablon.

\section{B. Studi Lapangan}

1. Observasi dilakukan dengan menganalisis alur Job description dari masing-masing stakeholder yang berhubungan dengan proses pelayanan kepada pelanggan. Observasi dilakukan dengan cara mengamati proses penyampaian informasi yang dibutuhkan pelanggan mengenai jasa yang dimiliki oleh perusahaan oleh customer service.

2. Wawancara dengan pemilik sablon dan konveksi sakti, dari hasil wawancara yang didapatkan yaitu mengenai beberapa informasi mengenai keadaan sistem yang sudah berjalan dan beberapa kekurangan yang dianggap butuh untuk ditambahkan, sehingga perlu dibuatkan sistem baru yang terintegrasi di sablon dan konveksi sakti. Dari beberapa pertanyaan yang diajukan kepada pemilik usaha sangat memungkinkan untuk dibuatkan sistem dalam meningkatkan pelayanan pelanggan.

3. Studi literatur sejenis dilakukan dengan melihat dan membaca beberapa literatur penelitian sejenis yang dijadikan sebagai acuan untuk menyelesaikan penelitian ini.

\section{Metodologi Pengembangan Sistem}

Pada tahap ini terdapat kegiatan analisa data \& perancangan sistem. Perancangan sistem informasi customer relationship management ini menggunakan metode SDLC dengan pendekatan waterfall model. Dalam waterfall model ini terdapat enam tahapan (perencanaan sistem, analisis sistem, design sistem, seleksi sistem, implementasi sistem dan maintenance sistem), namun dalam penelitian ini hanya sampai pada analisis sistem saja.

\section{III.HASIL DAN PEMBAHASAN}

\section{A. Perencanaan sistem}

Perencanaan sistem merupakan tahap pertama dalam pemodelan system development life cycle. Perencanaan sistem ini untuk mendefinisikan tujuan dan ruang lingkup pengembangan sistem dari pemasalahan yang ada dan memastikan pengembangan sistem yang akan diajukan layak untuk dikembangkan. Pada tahap ini dilakukan wawancara kepada seluruh pihak yaitu kepada pemilik UMKM SAKTI, Kepala produksi, Kepala keuangan dan yang bertanggung jawab di bagian administrasi. Hasil wawancara ini difokuskan terhadap pelayanan pelanggan.

Terdapat tiga permasalahan utama yang dirangkum dari wawancara ini yaitu pemilik usaha kesulitan dalam memantau pelanggan yang memiliki potensi besar agar dapat memberikan pelayanan yang berbeda dari pelanggan lainnya, pemilik usaha juga kesulitan memantau kegiatan produksi. Di bagian produksi kesulitan dalam menentukan list yang harus dikerjakan terlebih dahulu karena tidak ada SOP yang jelas, biasanya bagian produksi menerima perintah langsung dari pemilik mana yang harus dikerjakan terlebih dahulu. Selain itu hasil wawancara dengan bagian keuangan bahwa mereka kesulitan membuat laporan keuangan yang harus diketahui pemilik setiap bulannya. Rekap bulanan mereka tidak dilakukan secara rutin dan masih ditulis manual, sehingga mereka kesusahan apabila terjadi salah hitung dsb. Dari permasalahan ini diharapkan terdapat pengembangan sistem yang dapat membantu mempermudah dalam meningkatkan pelayanan terhadap pelanggan sehingga dapat meningkatkan loyalitas pelanggan.

\section{B. Analisis Kebutuhan}

Analisis kebutuhan merupakan tahapan setelah perencanaan sistem. Analisis kebutuhan dimulai dari sistem existing sehingga dapat mengetahui sistem yang ada. Permasalahan secara detail dapat dianalisa dan ditemukan solusi sehingga dapat dikembangkan. Analisis kebutuhan ini nantinya akan dianalisa dengan analisis SWOT agar mempermudah dalam mendapatkan solusi dari permasalahan yang ada sesuai dengan tujuan awal dari bisnis sablon dan konveksi yaitu meningkatkan pelayanan pelanggan.

Analisis Sistem Existing

Analisis sistem Existing yaitu proses yang dilakukan melalui wawancara kepada pihak yang terkait, yaitu pemilik usaha UMKM SAKTI. Untuk mengetahui kondisi sistem yang berjalan saat ini. Selain itu, agar kita dapat mengetahui permasalahanpermasalahan yang dihadapi oleh perusahaan (Douglas,2010).

a. Kondisi internal

Dalam menjalankan bisnis di Sakti sudah didiukung oleh beberapa faktor internal yang sudah dibentuk oleh pemiliki dengan proses bisnis yang terkait dengan operasional perusahaan. Dalam penerapannya pemilik dibantu oleh sumberdaya perusahaan. Untuk mendapatkan gambaran yang jelas, maka rincian dijelaskan pada poin-poin di bawah ini:

1) Strategi perusahaan

Setiap proses yang dijalankan oleh Sakti berdasarkan visi dan misi yang dibuat oleh perusahaan. Visi dan misi tersebut adalah 
Visi: Menjadi Perusahaan sablon kaos manual dan konveksi di Indonesia yang Profesional, Berkarakter, Inovatif, Produktif yang dapat memberi manfaat, serta mampu membuka lapangan pekerjaan yang menguntungkan bagi sesama.

Misi :

1. Membangun Usaha sablon kaos dan konveksi yang mampu memberikan pelayanan dan kepuasan bagi pelanggan.

2. Mengedepankan Kualitas produksi dengan harga yang terjangkau.

3. Menghadirkan lapangan pekerjaan yang profesional dengan situasi kerja yang produktif.

4. Menyantuni bagi mereka yang membutuhkan.

2) Sumberdaya Manusia

Sakti memberikan fasilitas terhadap karyawan yaitu diberi kesempatan untuk mengembangkan diri dengan cara mengikuti pelatihan sablon, pelatihan jahit, seminar bisnis dsb.

3) Infrastruktur

Sakti memiliki infrastruktur yang digunakan untuk mendukung operasional perusahaan. Infrastruktur yang dimiliki perusahaan yaitu Kantor pusat di jalan poncowati Desa Demangan Madiun, dan kantor cabang di jalan menganti hulaan, gresik serta tempat produksi di jalan raya menganti 64 gresik.

4) Jaringan Perusahaan

Jaringan perusahaan yaitu mencakup seluruh wilayah Indonesia, karena kami menjual produk melalui instagram, facebook dan shopee. Selain itu Sakti memiliki kantor cabang di Gresik sehingga jaringan perusahaan memiliki perluasan yang cukup besar dimana target utamanya sekitar gresik dan surabaya. Sakti juga sering menjadi sponsorshi dalam beberapa kegiatan untuk memperluas jaringan.

5) Produk

Sakti menawarkan produk keseluruh masyarakat Indoensia. Produk yang ditawarkan berupa kaos polos, kaos sablon, jaket, hoodie. Mereka juga menawarkan produk custom sesuai keinginan pembeli, selain itu mreka juga menerima makloon sablon dan makloon jahit.

6) Proses bisnis

Proses bisnis yang ada di Sakti untuk bagian customer service akan dijelaskan pada analisis sistem, yaitu proses bisnis sebelum ada perubahan.

b. Kondisi Eksternal

Selain kondisi internal yang ada di perusahaan, sakti juga memiliki kondisi eksternal yang perlu dipertimbangkan sebelum memutuskan strategi bisnis kedepannya. Kondisi eksternal tersebut diantaranya adalah sebagai berikut.

1) Pemerintahan

Pemerintah mendukung adanya UMKM dalam peraturan perundang-undangan yaitu Undang-Undang Nomor 20 Tahun 2008 Tentang Usaha Mikro, Kecil, dan Menengah. UU tersebut berkaitan erat dengan implementasi keuangan berkelanjutan di Indonesia (OJK.go.id) dan peraturan pemerintah no 17 Tahun 2013 dimana Poin penting yang diatur pada PP ini adalah peran pemerintah pusat dan pemerintah daerah untuk memfasilitasi pengembangan UMKM.

2) Ekonomi

Dalam hal ekonomi, terutama ekonomi lokal, sakti mencari sumber daya manusia yang berada tidak jauh dari tempat produksi sehingga kegiatan usaha yang dikerjakan berdamapak langsung terhadap lingkungan sekitar. Sakti juga memberi pelatihan khusus bagi SDM yang masih awam dengan usaha sablon dan konveksi.

3) Teknologi

Dalam hal teknologi sakti juga memanfaatkan media sosial untuk sarana promosi dan melebarkan jaringan perusahaan. Sakti juga sering menjadi sponshorsip untuk kegiatan-kegiatan skala kecil maupun skala besar. Untuk administrasi dan keungan sakti memanfaatkan microsoft office sebagai media pembuatan laporan admnistras dan keuangan perusahaan

c. Analisis SWOT

Setelah dianalisis sistem existing perusahaan sakti, maka kita dapat mengidentifikasi kompetensi perusahaan dengan analisis SWOT

Tabel 1. Analisis Strength/Weakness

\begin{tabular}{lcl}
\hline $\begin{array}{l}\text { Faktor } \\
\text { Internal }\end{array}$ & \multicolumn{1}{c}{ Strength/Weakness } \\
\hline 1. Strategi & $(+)$ & $\begin{array}{l}\text { Perusahaan fokus terhadap usaha dan } \\
\text { pengembangan SDM } \\
\text { Belum ada tujuan yang jelas di } \\
\text { perusahaan }\end{array}$ \\
& $(-)$ & $\begin{array}{l}\text { Karyawan belum memiliki keterampilan } \\
\text { di bidang sablon dan konveksi } \\
\text { Masih ada karyawan yang digaji } \\
\text { borongan } \\
\text { 2. Sumber daya } \\
\text { manusia }\end{array}$ \\
& $(-)$ baik \\
\hline
\end{tabular}




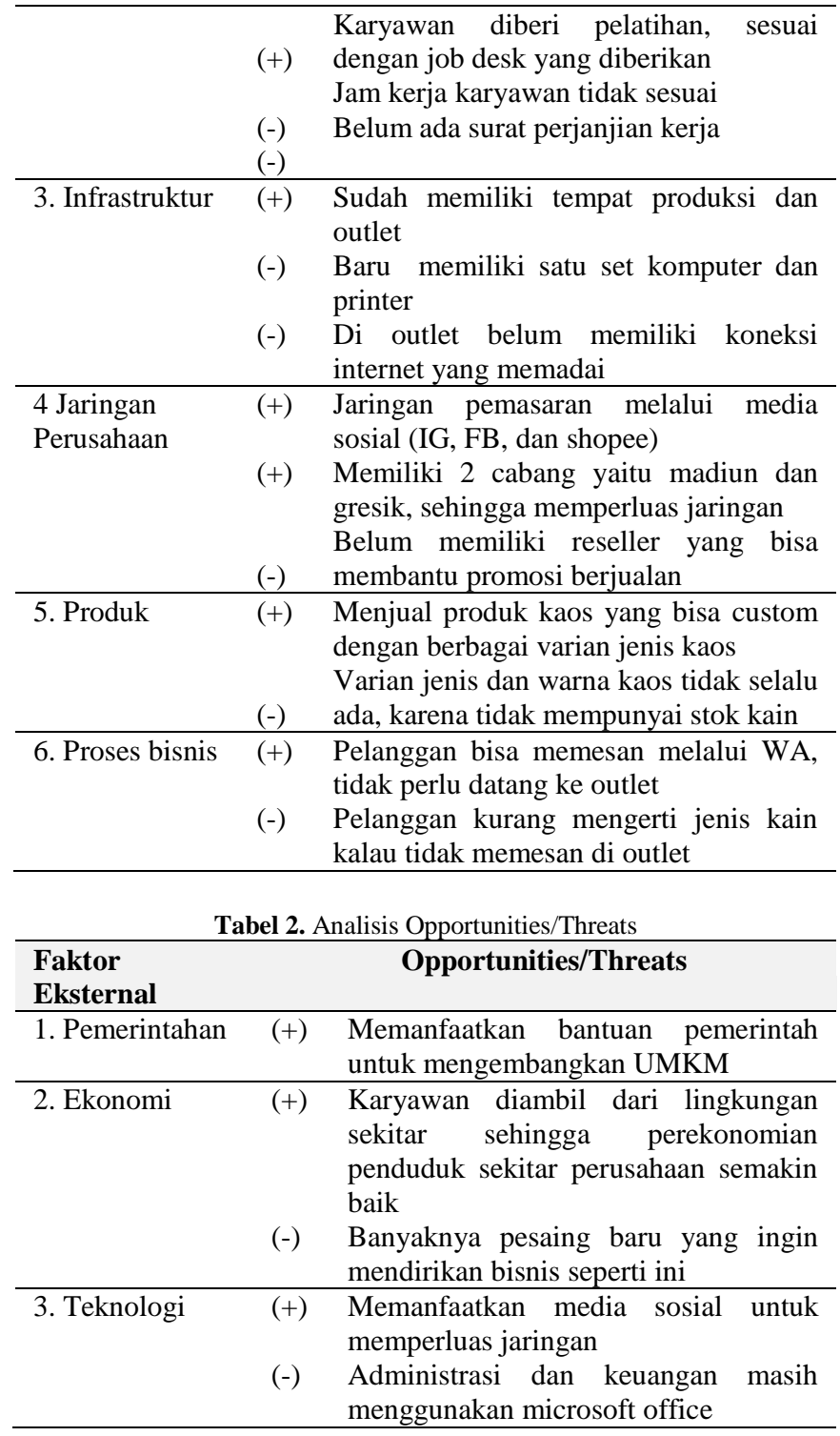

Berdasarkan identifikasi faktor internal dan faktor eksternal, maka hasil analisis SWOT adalah sebagai berikut:

Tabel 3. Hasil analisis SWOT

\begin{tabular}{l} 
Strength \\
1. Perusahaan fokus terhadap usaha dan \\
pengembangan SDM \\
2. Cara pelayanan pelanggan sudah cukup baik \\
3. Karyawan diberi pelatihan, sesuai dengan job \\
desk yang diberikan \\
4. Sudah memiliki tempat produksi dan outlet \\
5. Jaringan pemasaran melalui media sosial (IG, \\
FB, dan shopee) \\
6. Memiliki 2 cabang yaitu madiun dan gresik, \\
sehingga memperluas jaringan \\
7. Menjual produk kaos yang bisa custom \\
dengan berbagai varian jenis kaos \\
8. Pelanggan bisa memesan melalui WA, tidak \\
perlu datang ke outlet \\
1. Belum ada tujuan yang jelas di perusahaan \\
2. Karyawan belum memiliki keterampilan di \\
bidang sablon dan konveksi \\
3. Masih ada karyawan yang digaji borongan \\
4. Jam kerja karyawan tidak sesuai \\
5. Belum ada surat perjanjian kerja \\
6. Belum memiliki reseller yang bisa membantu \\
\hline
\end{tabular}




\begin{tabular}{|c|c|}
\hline & $\begin{array}{l}\text { promosi berjualan } \\
\text { 7. Varian jenis dan warna kaos tidak selalu ada, } \\
\text { karena tidak mempunyai stok kain } \\
\text { 8. Pelanggan kurang mengerti jenis kain kalau } \\
\text { tidak memesan di outlet }\end{array}$ \\
\hline Opportunities & 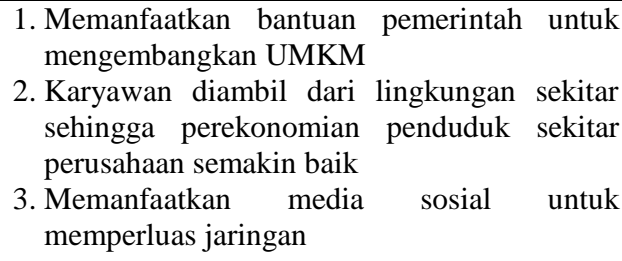 \\
\hline Treaths & $\begin{array}{l}\text { 1. Banyaknya pesaing baru yang ingin } \\
\text { mendirikan bisnis seperti ini } \\
\text { 2. Administrasi dan keuangan masih } \\
\text { menggunakan microsoft office }\end{array}$ \\
\hline
\end{tabular}

Selanjutnya perlu penggambaran secara jelas bagaimana peluang dan ancaman eksternal yang dihadapi perusahaan dapat disesuaikan dengan kekuatan dan kelemahan yang dimiliki. Dari hasil analisis diatas dapat menghasikan empat set alternative strategis. Yaitu :

1. Strategi Strength- Opportunity (SO)

a. Memanfaatkan media sosial untuk memperluas jaringan $(\mathrm{S} 5,6, \mathrm{O} 3)$

b. Memanfaatkan kegiatan yang diadakan oleh pemerintah, seperti pelatihan-pelatihan bisnis dan skill $(\mathrm{S} 1,3, \mathrm{O} 1)$

2. Strategi Strength-Treaths (ST)

a. Memberikan pelayanan pelanggan dengan baik, (S2,4,7,8, T1)

b. Perusahaan fokus terhadap pengembangan usaha sehingga dengan adanya pesaing tidak menjadi ancaman bagi perusahaan $(\mathrm{S} 1, \mathrm{~T} 1)$

3. Strategi Weakness-Opportunity (WO)

a. Membuat tujuan yang jelas di perusahaan

b. Karyawan lebih diperhatikan, terutama mengenai jam kerja karyawan dan surat perjanjian kerja

c. Dibangun sistem yang terintegrasi mengenai pemesanan barang, data pelanggan dan rekap bulanan

4. Strategi Weakness-Treaths (WT)

Komitmen untuk menjalin hubungan dan komunikasi dengan pelanggan khususnya pelanggan yang berpotensi (W8,T1)

\section{Analisis Sistem}

Analisa sistem dilakukan untuk mendapatkan semua kebutuhan yang diperlukan dalam membangun sistem. Analisis kebutuhan dilakukan dengan cara mengidentifikasi kebutuhan sistem serta siapa saja yang terlibat didalamnya. (Sofyana,2018) Sistem CRM yang berlaku sebelumya adalah sebagai berikut:

1. Bagian customer service (admin)

a. Pesan Kaos

Pelanggan bisa memesan kaos dengan datang langsung ke toko atau melalui WA, kemudian admin menjelaskan secara detail harga produk yang ditawarkan sablon kepada pelanggan. Apabila pelanggan sepakat dengan harga, proses selanjutnya adalah memberikan form pemesanan kaos dan sablon. Pelanggan mengisi form tersebut dan mengirimkan detail design yang akan di sablon. Apabila pelanggan belum mempunyai design maka pelanggan akan diarahkan ke bagian design. untuk yang memesan melalui WA, admin akan meneruskan detail design yang diinginkan pelanggan ke bagian design. Apabila design sudah disepakati, admin memberikan form pemesanan kaos dan sablon ke bagian produksi. Apabila proses produksi sudah selesai, admin akan memberitahu pelanggan bahwa pesanan sudah selesai dan bisa diambil

b. Complain pelanggan

Apabila pelanggan merasa hasil produksi tidak sesuai dengan form pemesanan, pelanggan bisa melakukan complain dalam jangka waktu 1x24 jam. Misal ada cacat sablon atau cacat kaos, maka akan diganti dengan yang baru. Alurnya hampir sama dengan pesan kaos.

c. Rekap pemesanan yang masuk

Admin juga bertugas untuk merekap semua pesanan yang masuk tiap hari dan memperhatikan deadline pesanan yang dilakukan oleh pelanggan. Kemudian admin membuat daftar pesanan yang ada berdasarkan yang harus dikerjakan dulu oleh bagian produksi sesuai deadline pesanan

d. Rekap pemesanan yang sudah selesai di proses

Admin bertugas merekap semua pesanan yang sudah selesai untuk diteruskan di bagian keuangan dan dilaporkan ke pemilik setiap bulannya. 
Terdapat 3 aplikasi pada CRM. Pengaplikasian CRM antara lain SFA atau Sales Force Automation, CSS atau Customer Service and Support, dan EMA atau Entreprise Marketing Automation. SFA membantu dalam bidang penjualan, CSS di bidang pelayanan konsumen, dan EMA di bidang pemasaran. Sedangkan E-CRM sendiri merupakan penerapan strategi CRM dengan menggunakan media elektronik (Dyantina,2012).

Dilihat dari analisis proses bisnis diatas, CRM dapat diterapkan pada bagian EMA atau bagian pemasaran, dan CSS atau bagian pelayanan pelanggan.

CRM sendiri terdapat tiga fase yaitu: acquire (menarik pelanggan baru), enchance (meningkatkan kemampuan untuk menghasilkan keuntungan dari pelanggan yang telah ada), dan retain (mempertahankan pelanggan yang menguntungkan untuk kelangsungan hidup). Demi memenuhi fase-fase CRM tersebut, maka dibutuhkan beberapa fungsional pada sistem yang akan dirancang (Soliman,2011).

Untuk memenuhi fase dari CRM diatas, berikut adalah hal-hal yang dibutuhkan dalam analisa dan perancangan sistem ECRM

2. Kebutuhan Fungsional

Fungsi-fungsi yang tercakup dalam sistem ini antara lain:

Tabel 4. Kebutuhan Fungsional

\begin{tabular}{ll}
\hline No. & Kebutuhan Fungsional \\
\hline 1. & Sistem memiliki fasilitas user mengakses sistem sesuai \\
& dengan hak akses dan untuk keluar dari sistem \\
2 & Sistem dapat menampilkan fungsi daftar member \\
3 & $\begin{array}{l}\text { Sistem dapat menampilkan informasi detail produk kaos } \\
\text { dan harga }\end{array}$ \\
4 & $\begin{array}{l}\text { Sistem memiiki fungsi untuk melakukan pemesanan } \\
\text { barang }\end{array}$ \\
5 & Sistem dapat menampilkan data pesanan \\
6 & Sistem dapat menampilkan riwayat pesanan \\
7 & $\begin{array}{l}\text { Sistem memiliki fungsi yang dapat menampilkan status } \\
\text { dan data pesanan barang }\end{array}$ \\
8 & $\begin{array}{l}\text { Sistem mampu menyimpan data member } \\
\text { Sistem mampu mengolah menampilkan laporan } \\
\text { pemesanan barang dan laporan pesanan yang sudah } \\
\text { selesai }\end{array}$ \\
10 & Sistem dapat digunakan untuk mengubah pemesanan \\
barang
\end{tabular}

3. Kebutuhan Non Fungsional

Kebutuhan non fungsional yang dibutuhkan antara lain:

a. Sistem mudah dipahami oleh pengguna

b. Sistem dapat memberikan informasi yang dibutuhkan oleh pengguna

c. Sistem dapat memberikan manfaat bagi pengguna

4. Arsitektur Sistem

Berdasarkan analisa di atas, dapat diketahui bahwa modul CRM yang dibutuhkan untuk sistem adalah Customer Service and Support (CSS) dan Entreprise Marketing Automation (EMA). CSS dapat mendukung pelayanan pelanggan seperti penanganan keluhan sehingga keluhan yang masuk dapat terkontrol dan segera diselesaikan. EMA membantu dalam hal penanganan pelanggan serta promosi.

Hasil penelitian dalam bentuk data merupakan bagian yang disajikan untuk menginformasikan hasil temuan dari penelitian yang telah dilakukan. Ilustrasi hasil penelitian dapat menggunakan grafik/tabel/gambar. Sedangkan pembahasan mengemukakan keterkaitan antar hasil penelitian dengan teori, perbandingan hasil penelitian dengan hasil penelitian lain yang sudah dipublikasikan. Pembahasan menjelaskan pula implikasi temuan yang diperoleh bagi ilmu pengetahuan dan pemanfaatannya.

\section{IV.KESIMPULAN}

Analisis sistem informasi customer relationship management ini dibuat berdasarkan kebutuhan user dimana proses ini sesuai dengan posisi user diperusahaan. Metode analisis SWOT digunakan untuk menganalisis kebutuhan user mulai dari pemilik usaha, bagian keuangan, bagian administrasi, dan bagian produksi dan pelanggan. Selain itu dianalisis juga sistem existing perusahaan yaitu faktor internal dan eksternal sablon dan konveksi sakti. Dari hasil analisis SWOT nanti akan dapat membantu proses pengambilan data lebih mudah dengan mengganti proses manual menjadi proses pengumpulan data secara otomatis.

Sedangkan berdasarkan hasil dan analisis sistem terhadap perusahaan dapat diketahui bahwa modul CRM yang dibutuhkan untuk sistem adalah Customer Service and Support (CSS) dan Entreprise Marketing Automation (EMA). 


\section{DAFTAR PUSTAKA}

Ayu, Farhani Dkk. (2018). Pengembangan Sistem Informasi E-CRM Berbasis Website pada Dinikoe Keramik. Vol 2 No 11 November 2018. JPTIIK. Malang Buttle, Francis., (2009). Customer Relationship Management: Concepts and Technology, 2nd ed., Butterworth-Heinemann, Burlington.

Douglas. M. Lambert. (2010). CRM as a business process. Journal of business \& industrial marketing

Dyantina, O., Afrina, M., \& Ibrahim, A. (2012). Penerapan Customer Relationship Management (CRM) Berbasis Web (Studi Kasus Pada Sistem Informasi Pemasaran di Toko YEN-YEN) 1,2,3, 4(2), 516-529.

Sofyana STT, Latjuba dkk. (2018). Business Architecture Planning with TOGAF Framework (Case Study:STIKES XYZ). UNIKAMA.Malang.

Soliman, Dr. Hisham Sayed. (2011). Customer Relationship Management and Its Relationship to the Marketing Performance. International Journal of Business and Social Science. 